\title{
Correction to: Monte Carlo Simulation of the Efficiency of Fluorescence Resonance Energy Transfer, FRET Phenomenon
}

\author{
Afrodita Liliana Boldea ${ }^{1,2}$. Dan Gabriel Ghita ${ }^{1}$ \\ Published online: 30 December 2021 \\ ๑) Springer Science+Business Media, LLC, part of Springer Nature 2021

\section{Correction to: Journal of Fluorescence https://doi.org/10.1007/s10895-021-02822-0}

The original version of this article unfortunately contained a mistake. We want to add the below 'Acknowledgement' statement to our paper. The original article has been corrected.

Acknowledgements One of the authors (LAB) acknowledge the financial support from the Ministry of Research, Innovation and Digitization under project PN 19,060,205/2019. "Many thanks to Professor Dan Gabriel Ghita, from the National Institute for Nuclear Physics and Engineering, IFIN-HH, ELI-NP, for the support given to the composition and coordination of this article."
Publisher's Note Springer Nature remains neutral with regard to jurisdictional claims in published maps and institutional affiliations.

The original article can be found online at https://doi.org/10.1007/ s10895-021-02822-0.

Afrodita Liliana Boldea

alinusha_b@yahoo.com

Dan Gabriel Ghita

dan.ghita@nipne.ro

1 National Institute for Physics and Nuclear Engineering,

Bucharest, Măgurele, Romania

2 University of Craiova, Craiova, Romania 